\title{
Produtividade e qualidade industrial do arroz de terras altas em função da disponibilidade hídrica e adubação ${ }^{1}$
}

\author{
Angela Cristina Camarim Alvarez Artigiani ${ }^{2}$, Carlos Alexandre Costa $\mathrm{Crusciol}^{2}$, \\ Orivaldo $\mathrm{Arf}^{3}$, Rita de Cássia Felix Alvarez ${ }^{4}$, Adriano Stephan Nascente ${ }^{5}$
}

\begin{abstract}
Upland rice yield and milled quality

as affected by hydric availability and fertilization

The combination of nitrogen and silicon fertilization, in adequate amounts, can increase rice grains yield and quality. This study aimed at evaluating the yield components, grain yield and milled quality of rice grains, Primavera cultivar, according to the application of silicon combined with topdressing nitrogen fertilization, with and without irrigation, in Selvíria, Mato Grosso do Sul State, Brazil. The experimental design was randomized blocks, in a split-split-plot arrangement, with four replications. The treatments consisted of cropping systems (rainfed and sprinkler irrigation) for plots, silicon doses $\left(0 \mathrm{~kg} \mathrm{ha}^{-1}\right.$ and $100 \mathrm{~kg} \mathrm{ha}^{-1}$ ) for split-plots and topdressing nitrogen doses $\left(0 \mathrm{~kg} \mathrm{ha}^{-1}, 30 \mathrm{~kg} \mathrm{ha}^{-1}, 60 \mathrm{~kg} \mathrm{ha}^{-1}\right.$ and $\left.90 \mathrm{~kg} \mathrm{ha}^{-1}\right)$ for split-splitplots. Irrigation increased plant height and grain yield, and the silicon application did not affect grain yield and its components or the milled rice yield of irrigated rice. The rise of $\mathrm{N}$ doses, under sprinkler irrigation, increased plant height, number of tillers and panicles $\mathrm{m}^{-2}$ and total spikelets, as well as grain yield, however, for the rainfed system, rice yield decreased.
\end{abstract}

KEY-WORDS: Oryza sativa L.; silicate; nitrogen; cropping systems.

\section{INTRODUÇÃO}

A área plantada com arroz, no ecossistema terras altas, corresponde a cerca de $65 \%$ do total cultivado no Brasil, entretanto, a produtividade é baixa, representando apenas $41 \%$ da produção nacional (Conab 2011). Esta baixa produtividade é resultado da distribuição irregular de chuvas, nas principais regiões produtoras, o que compromete as fases de desenvolvimento da cultura (Heinemann \&

\section{RESUMO}

A combinação de adubações com nitrogênio e silício, em quantidades adequadas, pode aumentar a produtividade e a qualidade dos grãos de arroz. Este trabalho objetivou avaliar componentes de produção, produtividade e qualidade industrial de grãos de arroz, cultivar BRS Primavera, em função da aplicação de silício combinado com adubação nitrogenada em cobertura, em condições de sequeiro e irrigado, em Selvíria (MS). O delineamento experimental foi em blocos casualizados, em esquema de parcelas subsubdivididas, com quatro repetições. Os tratamentos foram constituídos pelos sistemas de cultivo (sequeiro e irrigação por aspersão), as subparcelas pela aplicação de silício $\left(0 \mathrm{~kg} \mathrm{ha}^{-1}\right.$ e $\left.100 \mathrm{~kg} \mathrm{ha}^{-1}\right)$ e as subsubparcelas por doses de nitrogênio em cobertura $\left(0 \mathrm{~kg} \mathrm{ha}^{-1}, 30 \mathrm{~kg} \mathrm{ha}^{-1}, 60 \mathrm{~kg} \mathrm{ha}^{-1} \mathrm{e}\right.$ $\left.90 \mathrm{~kg} \mathrm{ha}^{-1}\right)$. A irrigação proporcionou aumento na altura da planta e produtividade de grãos, e a aplicação de silício não alterou os componentes da produção e a produtividade de grãos, nem interferiu no rendimento industrial em cultivo irrigado. $\mathrm{O}$ aumento das doses de N, no sistema irrigado por aspersão, incrementou a altura, número de colmos e de panículas $\mathrm{m}^{-2}$, número total de espiguetas e a produtividade de grãos, no entanto, no sistema de sequeiro, a produtividade de grãos foi reduzida.

PALAVRAS-CHAVE: Oryza sativa L.; silicato; nitrogênio; sistemas de cultivo.

Stone 2009, Guimarães et al. 2011, Menezes et al. 2011). Adicionalmente, estes frequentes períodos de deficiência hídrica, que a planta sofre durante o ciclo, afetam a qualidade dos grãos (Arf et al. 2002).

Essa situação pode ser resolvida com a utilização de irrigação por aspersão, uma vez que, além da estabilidade e incremento da produtividade de grãos, com o uso da irrigação, o processo de enchimento dos grãos é contínuo, proporcionando aumento no número de espiguetas granadas e na massa de grãos

1. Trabalho recebido em mar./2012 e aceito para publicação em set./2012 ( $\mathrm{n}^{\circ}$ registro: PAT 17595).

2. Universidade Estadual Paulista (Unesp), Faculdade de Ciências Agronômicas, Departamento de Agricultura, Botucatu, SP, Brasil.E-mails: crusciol@fca.unesp.br, angela.artigiani@hotmail.com.

3. Universidade Estadual Paulista (Unesp), Faculdade de Engenharia, Departamento de Fitotecnia, Tecnologia de Alimentos e Socioeconomia, Ilha Solteira, SP, Brasil.E-mail: arf@agr.feis.unesp.br.

4. Universidade Federal de Mato Grosso do Sul (UFMS), Unidade Universitária de Chapadão do Sul, Chapadão do Sul, MS, Brasil.E-mail: rita.alvarez@ufms.br.

5. Embrapa Arroz e Feijão, Santo Antônio de Goiás, GO, Brasil.E-mail: adriano@cnpaf.embrapa.br. 
(Pinheiro et al. 1985, Heinemann \& Stone 2009, Crusciol et al. 2012). Neste sentido, objetivando-se maiores produtividades e melhor qualidade de grãos, combinações de adubações com nitrogênio e silício têm sido utilizadas (Santos et al. 2006, Ávila et al. 2010, Mauad et al. 2011).

O nitrogênio é um dos nutrientes mais importantes para os vegetais, sendo, em alguns casos, fator limitante para altas produtividades (Fageria et al. 2011, Nascente et al. 2011), mas, quando em excesso, pode promover aumento na altura da planta, predispondo-a ao acamamento, ao autosombreamento e à ocorrência de doenças (Crusciol et al. 2006). Estes efeitos podem ser amenizados com o uso do silício, uma vez que este elemento proporciona resistência ao acamamento e tolerância a doenças (Prabhu et al. 2007, Gomes et al. 2011, Gutierrez et al. 2011, Mauad et al. 2011).

Não existe consenso sobre a essencialidade do silício, no entanto, ele já é utilizado na adubação de algumas espécies vegetais, e é o nutriente mais extraído pela cultura do arroz (Ma et al. 2006, Ávila et al. 2010, Gomes et al. 2011, Gutierrez et al. 2011).

O rendimento de benefício e a proporção de grãos quebrados estão relacionados às características genéticas da cultivar, métodos de colheita e secagem dos grãos, condições climáticas após a floração e adubação (Barbosa Filho \& Fonseca 1994, Crusciol et al. 1999, Santos et al. 2006). Entretanto, ainda são poucos os trabalhos relacionando a adubação silicatada com a qualidade de grãos de arroz (Ávila et al. 2010).

Assim, este trabalho objetivou avaliar os componentes de produção, produtividade e qualidade industrial de grãos de arroz, cultivar Primavera, em função da aplicação de silício combinado com a adubação nitrogenada em cobertura, em condições de sequeiro e irrigação por aspersão.

\section{MATERIAL E MÉTODOS}

O experimento foi conduzido na safra 2006/2007, em Selvíria (MS) $\left(20^{\circ} 22^{\prime} \mathrm{S}, 51^{\circ} 22^{\prime} \mathrm{W}\right.$ e altitude de $335,0 \mathrm{~m})$, região caracterizada por clima tropical úmido, com estação chuvosa no verão e seca no inverno, apresentando umidade relativa do ar, temperatura e precipitação média anual de $70-80 \%, 23,5^{\circ} \mathrm{C}$ e $1.350 \mathrm{~mm}$, respectivamente. Adicionalmente, durante a condução do experimento, os dados de precipitação e temperaturas máximas e mínimas foram monitorados. O solo foi classificado como Latossolo Vermelho distrófico típico argiloso (Embrapa 1999).

Antes da instalação do experimento, realizou-se a caracterização química e granulométrica, na camada $0-0,20 \mathrm{~m}$, segundo metodologia proposta por Raij et al. (2001), cujos resultados foram: $\mathrm{pH}\left(\mathrm{CaCl}_{2}\right)=4,7$; M.O. $=17 \mathrm{~g} \mathrm{~kg}^{-1}$; $\mathrm{P}$ (resina) $=$ $9 \mathrm{mg} \mathrm{dm}^{-3} ; \mathrm{Si}=43 \mathrm{mg} \mathrm{dm}^{-3} ; \mathrm{K}=1,3 \mathrm{mmol}_{\mathrm{c}} \mathrm{dm}^{-3}$; $\mathrm{Ca}=15 \mathrm{mmol}_{\mathrm{c}} \mathrm{dm}^{-3} ; \mathrm{Mg}=9,0 \mathrm{mmol}_{\mathrm{c}} \mathrm{dm}^{-3} ; \mathrm{H}+\mathrm{Al}=$ $34 \mathrm{mmol} \mathrm{dm}^{-3}$; saturação por bases $=43 \%$; areia $=$ $220 \mathrm{~g} \mathrm{~kg}^{-1}$; silte $=120 \mathrm{~g} \mathrm{~kg}^{-1}$; e argila $=660 \mathrm{~g} \mathrm{~kg}^{-1}$.

O delineamento experimental foi em blocos casualizados, em esquema de parcelas subsubdivididas, com quatro repetições. As parcelas foram constituídas pelos sistemas de cultivo (sequeiro e irrigado por aspersão), as subparcelas por doses de silício $\left(0 \mathrm{~kg} \mathrm{ha}^{-1}\right.$ e $100 \mathrm{~kg} \mathrm{ha}^{-1}$ ) as subsubparcelas por doses de nitrogênio em cobertura $\left(0 \mathrm{~kg} \mathrm{ha}^{-1}, 30 \mathrm{~kg} \mathrm{ha}^{-1}, 60 \mathrm{~kg} \mathrm{ha}^{-1}\right.$ e $90 \mathrm{~kg} \mathrm{ha}^{-1}$ ). Cada subsubparcela foi constituída por seis linhas de 6,0 m de comprimento, espaçadas em $0,33 \mathrm{~m}$, sendo a área útil as três linhas centrais, desprezando-se $0,5 \mathrm{~m}$ das extremidades.

A semeadura foi realizada manualmente, no dia 25 de novembro, utilizando-se a cultivar BRS Primavera, na densidade de 100 sementes $\mathrm{m}^{-2}$, sendo estas previamente tratadas com carbofuran (1,5 $\mathrm{kg} \mathrm{ha}^{-1}$ do i.a.). A adubação de semeadura foi de $250 \mathrm{~kg} \mathrm{ha}^{-1}$ da fórmula (NPK) 04-30-10 + 0,4\% Zn. Logo após a semeadura, no tratamento com silício, foram aplicados, no sulco, $100 \mathrm{~kg} \mathrm{ha}^{-1} \mathrm{de} \mathrm{Si}$, na forma de silicato de $\mathrm{Ca}$ e $\mathrm{Mg}$ ( $42 \%$ de $\mathrm{CaO} ; 12 \%$ de $\mathrm{MgO}$; $23 \%$ de $\mathrm{SiO}_{2} ; 0,42 \%$ de $\mathrm{P}_{2} \mathrm{O}_{5} ; 0,19 \%$ de $\mathrm{K}_{2} \mathrm{O} ; 0,37 \%$ de $\mathrm{SO}_{3} ; 11 \%$ de $\mathrm{Fe}_{2} \mathrm{O}_{3} ; 1,8 \%$ de $\mathrm{MnO} ; 0,4 \mathrm{mg} \mathrm{g}^{-1} \mathrm{de}$ Mo; e $0,133 \mathrm{mg} \mathrm{g}^{-1} \mathrm{de} \mathrm{Zn}$ ). A emergência da cultura ocorreu no dia 2 de dezembro.

Nas unidades experimentais irrigadas, utilizou-se sistema fixo de irrigação convencional por aspersão, com vazão de $3,3 \mathrm{~mm} \mathrm{~h}^{-1}$ nos aspersores. No manejo de água, foram utilizados três coeficientes de cultura $(\mathrm{Kc})$, distribuídos em quatro períodos compreendidos entre a emergência e a colheita. Para a fase vegetativa, foi utilizado o valor de 0,4 ; para a reprodutiva, inicial de 0,7 e final de 1,0; e, para a fase de maturação, estes valores foram invertidos, ou seja, inicial de 1,0 e final de 0,7 , conforme sugerido por Rodrigues et al. (2004). Assim, o controle dos tratamentos irrigados, considerando-se a profundidade de exploração do sistema radicular de $0,2 \mathrm{~m}$, foi iniciado com a capacidade de água disponível (CAD) no seu 
máximo (16,8 mm), subtraindo-se, sucessivamente, o valor da evapotranspiração da cultura (ETc), até que o total de água atingisse limite mínimo de $40 \%$ da CAD $(6,7 \mathrm{~mm})$.

A evaporação de água (ECA) foi obtida diariamente do tanque Classe A instalado no posto agrometeorológico da Fazenda de Ensino e Pesquisa da Unesp, Campus de Ilha Solteira (SP), distante, aproximadamente, 500,0 $\mathrm{m}$ do local. O coeficiente do tanque Classe A(Kp) foi o proposto por Doorenbos \& Pruitt (1976), o qual é função da área circundante, velocidade do vento e umidade relativa do ar. Desta forma, foram aplicadas as seguintes lâminas d'água: $13,8 \mathrm{~mm}(07 / 12) ; 12,6 \mathrm{~mm}(13 / 12) ; 11,6 \mathrm{~mm}$ (17/12); $14,4 \mathrm{~mm}(26 / 12) ; 13,2 \mathrm{~mm}(30 / 12) ; 14,6 \mathrm{~mm}(06 / 02)$; e $12,4 \mathrm{~mm}(06 / 02)$, totalizando $92,6 \mathrm{~mm}$ irrigados.

A adubação nitrogenada em cobertura foi realizada com ureia, aos 31 dias após a emergência (DAE) das plântulas de arroz, próximo à diferenciação floral. O controle de plantas daninhas foi efetuado aplicando-se os herbicidas oxadiazon $\left(750 \mathrm{~g} \mathrm{ha}^{-1} \mathrm{do}\right.$ i.a.), em pré-emergência, e, aos $17 \mathrm{DAE}$, foi aplicado bentazon ( $720 \mathrm{~g} \mathrm{ha}^{-1}$ do i.a.). Após este período, foram realizadas apenas capinas manuais. A emergência das plantas ocorreu oito dias após a semeadura, o florescimento aos 66 DAE $(08 / 02)$ e a maturação fisiológica aos 86 DAE (28/02).

A altura da planta foi obtida pela mensuração da distância média $(\mathrm{cm})$ compreendida entre a superfície do solo e a extremidade superior da panícula mais alta, determinada em 20 plantas ao acaso, na área útil de cada unidade experimental. Foram contados o número de colmos e de panículas contidas em $1,0 \mathrm{~m}^{2}$, na área útil de cada unidade experimental. Calculou-se a média do número de espiguetas panículas $^{-1}$, pela avaliação de 20 panículas por unidade experimental. A fertilidade das espiguetas foi determinada a partir da relação entre o número de espiguetas granadas por panícula e o número total de espiguetas por panícula, multiplicada por 100. A massa de 1.000 grãos foi obtida pela pesagem de quatro amostras de 1.000 grãos por unidade experimental (130 $\mathrm{g} \mathrm{kg}^{-1}$ base úmida). A produtividade de grãos foi avaliada mediante a colheita manual do arroz, após a maturação fisiológica, em duas linhas centrais de 5,0 m em cada subparcela, desprezando-se $0,50 \mathrm{~m}$ de cada lado da unidade experimental. As plantas foram trilhadas e os grãos secos. Os grãos foram pesados e os dados transformados para $\mathrm{kg} \mathrm{ha}^{-1}\left(130 \mathrm{~g} \mathrm{~kg}^{-1}\right.$ base úmida).
Para a avaliação do rendimento de benefício, retirou-se amostra de $100 \mathrm{~g}$ do arroz colhido, passando-a em engenho de prova Suzuki, modelo MT, por 1 minuto. Em seguida, foram pesados os grãos brunidos e o valor encontrado foi considerado como rendimento de benefício (\%). Posteriormente, os grãos brunidos foram colocados no "trieur" $\mathrm{n}^{\mathrm{o}} 2$, por 30 segundos. Assim, pesaram-se os grãos que permaneceram no "trieur" e o valor obtido foi considerado como grãos inteiros e os demais como grãos quebrados, ambos expressos em percentagem.

Os dados resultantes foram submetidos à análise de variância, sendo realizado o teste Tukey, a 5\%. Adicionalmente, utilizou-se a análise de regressão, para o fator doses de $\mathrm{N}$.

\section{RESULTADOS E DISCUSSÃO}

Houve efeito significativo dos sistemas de cultivo na altura da planta, sendo que, no cultivo sob irrigação, as plantas de arroz tiveram maior altura (Tabela 1). Os dados foram ajustados à equação polinomial de segundo grau, com relação à adubação nitrogenada, nos dois sistemas de cultivo (sequeiro e irrigado) (Figura 1A). A maior disponibilidade hídrica, provavelmente, contribuiu para maior absorção do $\mathrm{N}$, o que refletiu na altura da planta, já que este nutriente é o que mais afeta esse parâmetro (Arf et al. 2002). Resultados semelhantes foram observados por Crusciol et al. (1999), Fageria et al. (2011) e Guimarães et al. (2011).

A altura de planta aumentou de forma linear, com a adubação nitrogenada, na ausência de Si (Figura 1B). Com a aplicação deste elemento (Si), os dados foram ajustados à equação polinomial de segundo grau, em função dos níveis de $\mathrm{N}$, com a maior altura de plantas, na dose de $71 \mathrm{~kg} \mathrm{ha}^{-1}$ de $\mathrm{N}$, diminuindo para a maior dose de N (Figura 1B), ou seja, a adubação com silício proporcionou a maior altura de plantas, com menores níveis de $\mathrm{N}$.

No que se refere ao número de colmos $\mathrm{m}^{-2}$, houve interação entre sistemas de cultivo e doses de silício (Tabela 2), entre sistemas de cultivo e doses de nitrogênio (Figura 1C) e entre doses de silício e doses de nitrogênio (Figura 1D). Assim, no cultivo irrigado, constatou-se maior número de colmos $\mathrm{m}^{-2}$ (204 colmos $\mathrm{m}^{-2}$ ) na ausência da aplicação de $\mathrm{Si}$, diferindo do cultivo de sequeiro (184 colmos $\mathrm{m}^{-2}$ ) (Tabela 2). Neste caso, a maior disponibilidade hídrica proporcionou maior perfilhamento das plan- 
Tabela 1. Altura de plantas, número de colmos $\mathrm{m}^{-2}$ e panículas $\mathrm{m}^{-2}$, número total de espiguetas por panícula, fertilidade das espiguetas (FE), massa de 1.000 grãos (M1000), produtividade de grãos, rendimento de benefício (RB), rendimento de grãos inteiros (RI) e grãos quebrados (GQ) obtidos em arroz, em função do sistema de cultivo (SC) e doses de nitrogênio e silício (Selvíria, MS, safra 2006/2007).

\begin{tabular}{|c|c|c|c|c|c|c|c|c|c|c|}
\hline Fatores & Altura & Colmos & Panículas & Espiguetas & $\mathrm{FE}$ & M1000 & Produtividade & $\mathrm{RB}$ & RI & GQ \\
\hline Sistema Cultivo (SC) & $\mathrm{cm}$ & \multicolumn{2}{|c|}{ quantidade $\mathrm{m}^{-2}$} & quantidade & $\%$ & $\mathrm{~g}$ & $\mathrm{~kg} \mathrm{ha}^{-1}$ & \multicolumn{3}{|c|}{$\%$} \\
\hline Sequeiro & $104 b^{*}$ & $196 \mathrm{a}$ & $176 \mathrm{a}$ & $196 \mathrm{a}$ & $75 \mathrm{a}$ & $2,3 \mathrm{a}$ & $2.593 \mathrm{~b}$ & $74 \mathrm{a}$ & $60 \mathrm{a}$ & $14 \mathrm{a}$ \\
\hline Aspersão & $110 \mathrm{a}$ & $194 \mathrm{a}$ & $179 \mathrm{a}$ & $200 \mathrm{a}$ & $76 \mathrm{a}$ & $2,4 \mathrm{a}$ & $3.398 \mathrm{a}$ & $74 \mathrm{a}$ & $63 \mathrm{a}$ & $11 \mathrm{a}$ \\
\hline \multicolumn{11}{|l|}{ Silicio (Si) } \\
\hline 0 & $106 \mathrm{a}$ & $200 \mathrm{a}$ & $181 \mathrm{a}$ & $199 \mathrm{a}$ & $76 \mathrm{a}$ & $2,4 \mathrm{a}$ & $3.030 \mathrm{a}$ & $74 \mathrm{a}$ & $62 \mathrm{a}$ & $12 \mathrm{a}$ \\
\hline 100 & $107 \mathrm{a}$ & $190 \mathrm{a}$ & $175 \mathrm{a}$ & $197 \mathrm{a}$ & $75 \mathrm{a}$ & $2,4 \mathrm{a}$ & $2.960 \mathrm{a}$ & $73 \mathrm{a}$ & $61 \mathrm{a}$ & $12 \mathrm{a}$ \\
\hline \multicolumn{11}{|l|}{ Nitrogênio (N) } \\
\hline 0 & 99 & 170 & 155 & 181 & 78 & 2,5 & 2.567 & 73 & 61 & 12 \\
\hline 30 & 107 & 205 & 187 & 190 & 75 & 2,4 & 3.195 & 74 & 62 & 12 \\
\hline 60 & 109 & 194 & 174 & 208 & 76 & 2,4 & 3.213 & 75 & 63 & 12 \\
\hline 90 & 111 & 211 & 195 & 214 & 73 & 2,2 & 3.005 & 73 & 60 & 14 \\
\hline Teste F & \multicolumn{10}{|c|}{ Probabilidade do teste $F$} \\
\hline Blocos & 0,3210 & 0,4198 & 0,3712 & 0,4872 & 0,1712 & 0,1175 & 0,2309 & 0,0981 & 0,3543 & 0,4106 \\
\hline $\mathrm{SC}$ & $<0,001$ & 0,1703 & 0,0567 & 0,0504 & 0,0887 & 0,0567 & $<0,001$ & 0,1127 & 0,2202 & 0,3187 \\
\hline $\mathrm{Si}$ & 0,1298 & 0,1197 & 0,0714 & 0,0674 & 0,0902 & 0,0987 & 0,2185 & 0,2203 & 0,2926 & 0,1923 \\
\hline $\mathrm{N}$ & 0,0412 & $<0,001$ & $<0,001$ & $<0,001$ & 0,0267 & 0,0521 & 0,0378 & 0,0596 & 0,0899 & 0,0534 \\
\hline $\mathrm{SC} \times \mathrm{Si}$ & 0,2341 & 0,0310 & 0,0324 & 0,0427 & 0,1197 & 0,0487 & 0,2358 & 0,1007 & 0,2853 & 0,3103 \\
\hline $\mathrm{SC} \times \mathrm{N}$ & $<0,001$ & 0,0271 & 0,0437 & 0,0366 & 0,0254 & 0,0132 & $<0,001$ & 0,0376 & 0,0437 & 0,0448 \\
\hline Si x N & $<0,001$ & 0,0269 & 0,0416 & 0,0498 & 0,0277 & $<0,001$ & 0,0431 & 0,2218 & 0,0452 & 0,0399 \\
\hline $\mathrm{SC} \times \mathrm{Si} \times \mathrm{N}$ & 0,1004 & 0,2665 & 0,1187 & 0,2345 & 0,4462 & 0,3987 & 0,4491 & 0,3759 & 0,2236 & 0,1965 \\
\hline CV A $(\%)$ & 5,7 & 18,1 & 14,2 & 3,8 & 3,8 & 5,1 & 14,4 & 1,6 & 7,7 & 21,0 \\
\hline CV B (\%) & 3,6 & 11,8 & 12,4 & 10,9 & 4,0 & 4,1 & 14,7 & 1,7 & 4,4 & 11,9 \\
\hline CV C (\%) & 6,6 & 12,2 & 11,1 & 9,7 & 4,9 & 7,3 & 13,8 & 2,0 & 6,0 & 8,8 \\
\hline
\end{tabular}

* Médias seguidas da mesma letra minúscula, na coluna, não diferem estatisticamente entre si, pelo teste Tukey, a 5\%.

Tabela 2. Número de colmos $\mathrm{m}^{-2}$, número de panículas $\mathrm{m}^{-2}$, número total de espiguetas panícula ${ }^{-1} \mathrm{e}$ massa de 1.000 grãos de arroz, em função do sistema de cultivo e adubação silicatada (Selvíria, MS, safra 2006/2007).

\begin{tabular}{|c|c|c|}
\hline \multirow{2}{*}{$\begin{array}{l}\text { Sistema de } \\
\text { cultivo }\end{array}$} & \multicolumn{2}{|c|}{ Silício } \\
\hline & $\operatorname{Sem}\left(0 \mathrm{~kg} \mathrm{ha}^{-1}\right)$ & $\operatorname{Com}\left(100 \mathrm{~kg} \mathrm{ha}^{-1}\right)$ \\
\hline & \multicolumn{2}{|c|}{ Número de colmos $m^{-2}$} \\
\hline Sequeiro & 196 a A* & 196 a A \\
\hline \multirow[t]{2}{*}{ Irrigado } & 204 a A & $184 \mathrm{a} \mathrm{B}$ \\
\hline & \multicolumn{2}{|c|}{ Número de panículas $m^{-2}$} \\
\hline Sequeiro & 173 a A & 180 a A \\
\hline \multirow{2}{*}{ Irrigado } & 188 a A & 170 a B \\
\hline & \multicolumn{2}{|c|}{ Número total de espiguetas panícula ${ }^{-1}$} \\
\hline Sequeiro & 193 b A & 199 a A \\
\hline \multirow[t]{2}{*}{ Irrigado } & 205 a A & 195 a A \\
\hline & \multicolumn{2}{|c|}{ Massa de 1.000 grãos $(g)$} \\
\hline Sequeiro & $2,4 \mathrm{aA}$ & $2,3 \mathrm{bB}$ \\
\hline Irrigado & $2,4 \mathrm{aA}$ & $2,4 \mathrm{aA}$ \\
\hline
\end{tabular}

tas, como observado, também, por Guimarães et al. (2011).

Verificou-se aumento linear no número de colmos $\mathrm{m}^{-2}$ nos dois sistemas de cultivo, em função da adubação nitrogenada (Figura 1C). Resultados semelhantes foram obtidos por Barbosa Filho \& Fonseca (1994) e Fageria et al. (2011), que obtiveram aumento no número de perfilhos com a adubação nitrogenada, tanto em cultivo de sequeiro quanto irrigado por aspersão. Constatou-se, também, aumento linear, em função das doses de N, com a aplicação de $\mathrm{Si}$, evidenciando relação benéfica entre ambos. Entretanto, não houve interação para esta variável, na ausência da aplicação de Si (Figura 1D).

Para a característica número de panículas $\mathrm{m}^{-2}$, constatou-se maiores valores no cultivo irrigado por aspersão (Figura 1E) e na ausência da aplicação de silício (Tabela 2 e Figura 1F). O número de panículas por área é definido no período compreendido entre a germinação e até dez dias após a diferenciação do 

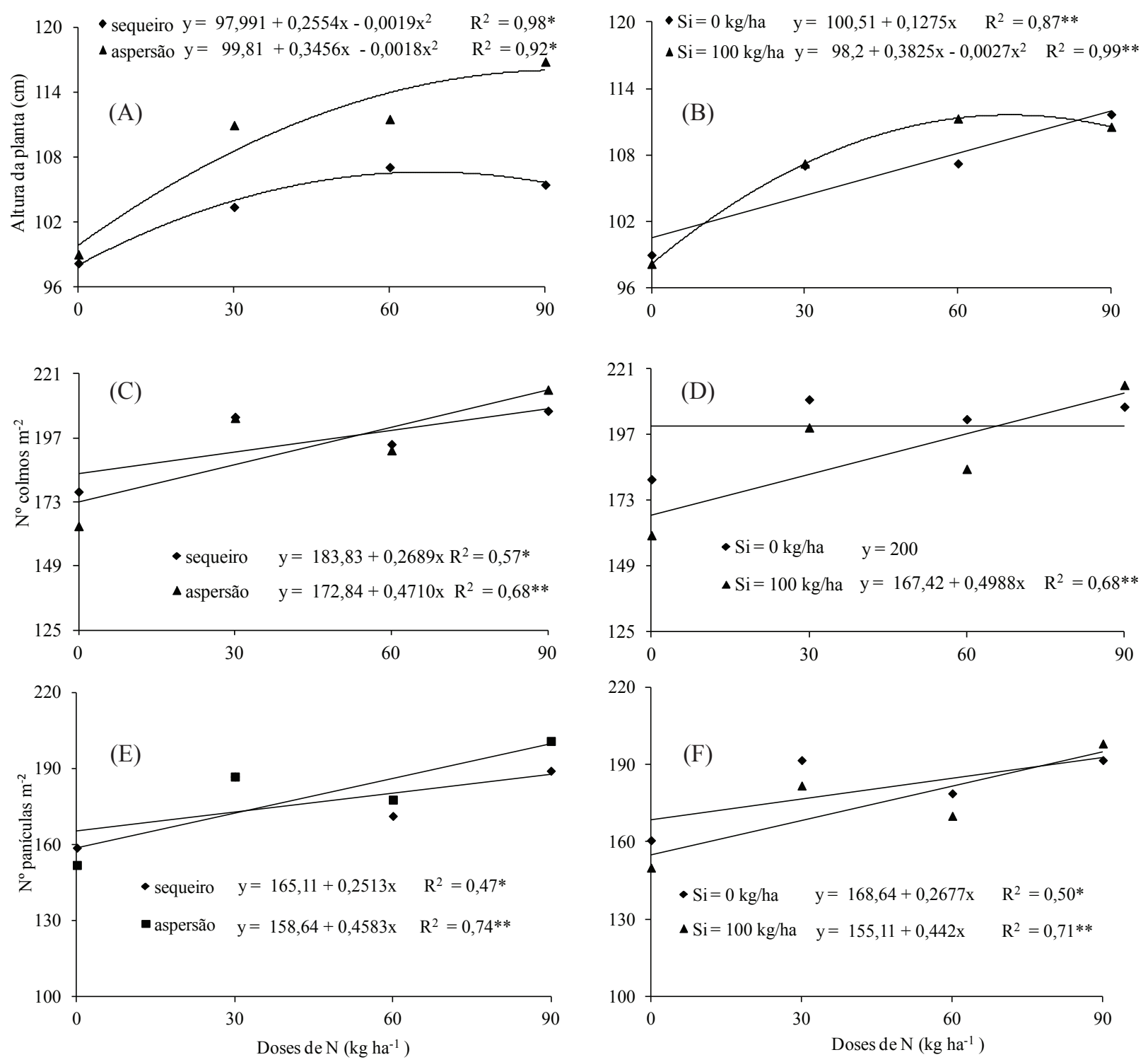

Figura 1. Altura de planta (A e B), número de colmos $\mathrm{m}^{-2}\left(\mathrm{C}\right.$ e D) e número de panículas $\mathrm{m}^{-2}$ (E e F) de arroz de terras altas, em função de sistemas de cultivo (sequeiro e irrigado) e adubação (nitrogenada e silicatada) (Selvíria, MS, safra 2006/2007).

primórdio da panícula (Santos et al. 2006), estando relacionado diretamente com o número de colmos por área, portanto, é dependente de fatores genéticos e ambientais. Dessa forma, a maior disponibilidade hídrica foi adequada para o perfilhamento das plantas, proporcionando maior número de colmos $\mathrm{m}^{-2}$, assim como para a transformação de gemas vegetativas em reprodutivas, resultando em maior número de panículas $\mathrm{m}^{-2}$. Resultados semelhantes foram obtidos por Heinemann \& Stone (2009).

Condições externas adversas, durante a diferenciação e o desenvolvimento inicial da panícula, podem provocar degenerações no primórdio floral ou na panícula jovem (Pinheiro et al. 1985). Assim, se ocorrer deficiência hídrica durante o período de transformação da gema vegetativa em reprodutiva, momento da passagem da fase vegetativa à fase reprodutiva, o número de panículas por área será afetado (Crusciol et al. 2006). Desta forma, pôde-se constatar que condições adequadas de disponibilidade hídrica, principalmente nas fases onde o número de panículas $\mathrm{m}^{-2}$ foi definido, promoveram maior desenvolvimento de panículas por área (Figura 1E).

$\mathrm{O}$ número de panículas $\mathrm{m}^{-2}$ aumentou linearmente, em função do aumento nas doses de N, nos tratamentos com e sem aplicação de Si (Figura 1F). 
Assim como ocorreu com a irrigação, as maiores doses de $\mathrm{N}$ também proporcionaram aumento do número de panículas, possivelmente devido ao fato de o nutriente também participar de funções estruturais na planta, como multiplicação e diferenciação celulares (Fageria et al. 2011, Nascente et al. 2011).

Com relação ao número total de espiguetas por panícula, no desdobramento da interação entre sistemas de cultivo e Si (Tabela 2), o maior número de espiguetas por panícula, no sistema irrigado por aspersão, foi obtido com a ausência de aplicação de Si. Na interação sistemas de cultivo e doses de N, verificou-se aumento linear neste componente de produção, nos dois sistemas de cultivo, em função da adubação nitrogenada (Figura 2A). Esta característica começa a ser definida desde a diferenciação do primórdio da panícula e vai até o emborrachamento (Santos et al. 2006). Além disto, depende do comprimento da ráquis, número de ramificações da ráquis e pontos de diferenciação de espiguetas nas ramificações, e é influenciado pela densidade de semeadura, adubação nitrogenada, radiação solar, disponibilidade hídrica, temperatura e cultivar. Desta forma, os processos de diferenciação e degeneração são extremamente sensíveis a níveis crescentes de N (Fageria et al. 2011). Também houve aumento linear na presença e ausência de $\mathrm{Si}$, em função da adubação nitrogenada (Figura 2B). No entanto, com a aplicação de $100 \mathrm{~kg} \mathrm{ha}^{-1} \mathrm{de} \mathrm{Si}$, a maior dose de $\mathrm{N}$ proporcionou maior número de espiguetas por panícula.

A fertilidade das espiguetas foi reduzida em condições de sequeiro, com o aumento dos níveis de N (Figura 2C). No entanto, para o sistema irrigado, não houve efeito significativo das doses de $\mathrm{N}$ (Figura 2D). Este componente da produção é dependente da meiose do grão de pólen (microsporogênese), da antese (abertura das anteras), polinização, fertilização e do início da fase de maturação, ou seja, quando se inicia a translocação de carboidratos, e é influenciado por condições adversas (doses excessivas de adubo nitrogenado, cultivo em solos salinos e condições climáticas desfavoráveis) que possam ocorrer no desenvolvimento da planta, principalmente em torno de 10 dias antes e após o florescimento (Santos et al. 2006, Ávila et al. 2010). Observou-se, também, redução da fertilidade nas espiguetas, com e sem a aplicação de $\mathrm{Si}$, com o aumento dos níveis de $\mathrm{N}$, sendo que, com a aplicação de $\mathrm{Si}$, a redução foi mais pronunciada (Figura 2D).
Com relação à massa de 1.000 grãos, constatou-se maiores valores na ausência da aplicação de $\mathrm{Si}$, no sistema de sequeiro (Tabela 2). Por outro lado, no sistema irrigado, a maior massa de grãos foi observada com a aplicação de $100 \mathrm{~kg} \mathrm{ha}^{-1} \mathrm{de} \mathrm{Si}$, a qual, provavelmente, contribuiu para maior acúmulo deste elemento na planta.

Apesar de não ter sido analisada a deposição de Si na casca de grãos de arroz, isto pode ter ocorrido e contribuído para o aumento da massa de grãos, conforme relatado por Balasta et al. (1989). Esta deposição de Si é atribuída à grande transpiração da panícula, na fase de enchimento do grão, visto que os processos de transporte e acúmulo de silício, nos tecidos vegetais, dependem da taxa de transpiração dos diferentes órgãos da planta (Ma et al. 2006, Ávila et al. 2010). Com este órgão em desenvolvimento, a transpiração tende a ser maior e, consequentemente, a deposição de Si pode ter sido maior, influenciando na massa de grãos.

Os valores da massa de 1.000 grãos foram ajustados às equações polinomial de segundo grau e linear, respectivamente para os sistemas de cultivo sequeiro e irrigado, diminuindo com o aumento das doses de N (Figura 2E). No entanto, a condição de sequeiro proporcionou menor massa de 1.000 grãos, com a adubação nitrogenada, o que pode ter ocorrido devido ao fato de a quantidade de carboidratos não ter sido suficiente para o enchimento de maior número de espiguetas produzidas. Estes resultados estão de acordo com os obtidos por Pinheiro et al. (1985) e Guimarães et al. (2011), que, também, relataram menor massa de 1.000 grãos, na ausência de irrigação. Houve redução na massa de 1.000 grãos, com o aumento das doses de nitrogênio, tanto na presença como na ausência de silício (Figura 2F). Os dados foram ajustados à equação linear, quando não se aplicou silício, e à polinomial de segundo grau, com a aplicação de $100 \mathrm{~kg} \mathrm{ha}^{-1}$ de Si.

A produtividade de grãos foi maior no sistema irrigado (Tabela 1) e os dados foram ajustados à função linear (Figura 2G). No sistema de sequeiro, os dados foram ajustados à equação polinomial de segundo grau, sendo a máxima produtividade obtida com a aplicação de $37 \mathrm{~kg} \mathrm{ha}^{-1} \mathrm{de} \mathrm{N}$.

A adubação nitrogenada induz a um maior perfilhamento e à formação de novas folhas, entretanto, caso não ocorra o adequado suprimento hídrico, pode haver quedas significativas de produtividade (Santos et al. 2006, Fageria et al. 2011). 

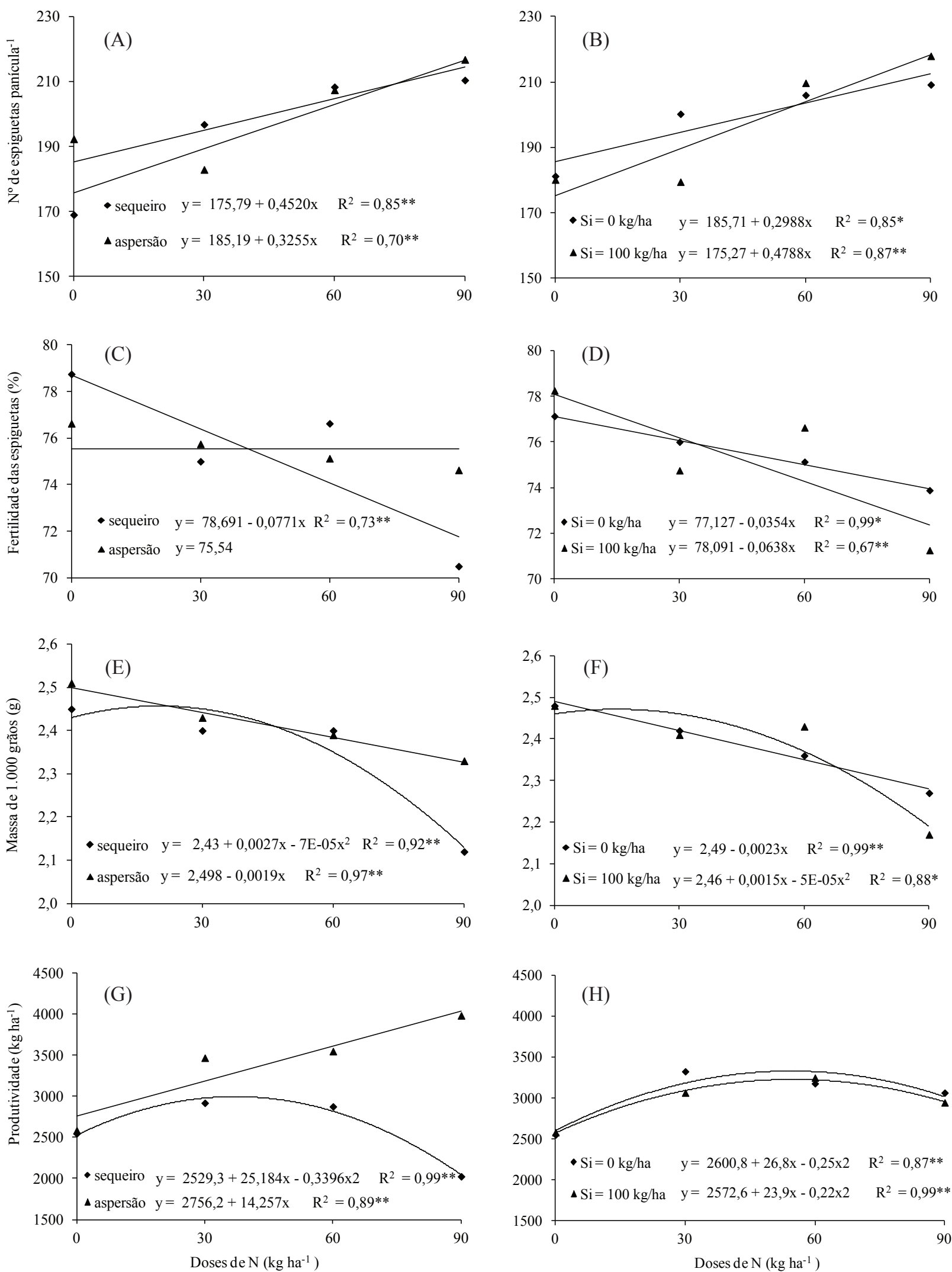

Figura 2. Número total de espiguetas por panícula ${ }^{-1}$ (A e B), fertilidade de espiguetas (C e D), massa de 1.000 grãos (E e F) e produtividade de arroz de terras altas, em função de sistemas de cultivo (sequeiro e irrigado) e adubação (nitrogenada e silicatada) (Selvíria, MS, safra 2006/2007). 
Os valores de produtividade, em relação às doses de nitrogênio, na presença e ausência de silício, foram ajustados às equações polinomiais de segundo grau (Figura 2H). Não houve efeito do Si sobre a produtividade, provavelmente devido à ausência de doenças e aos altos teores de Si normalmente encontrados nas plantas de arroz, já relatados por diversos autores (Gomes et al. 2011, Gutierrez et al. 2011, Mauad et al. 2011).

Com relação ao rendimento de benefício, não foi constatado efeito da aplicação de silício (Tabela 1). Este resultado esta de acordo com o observado por Reis et al. (2008), os quais destacaram
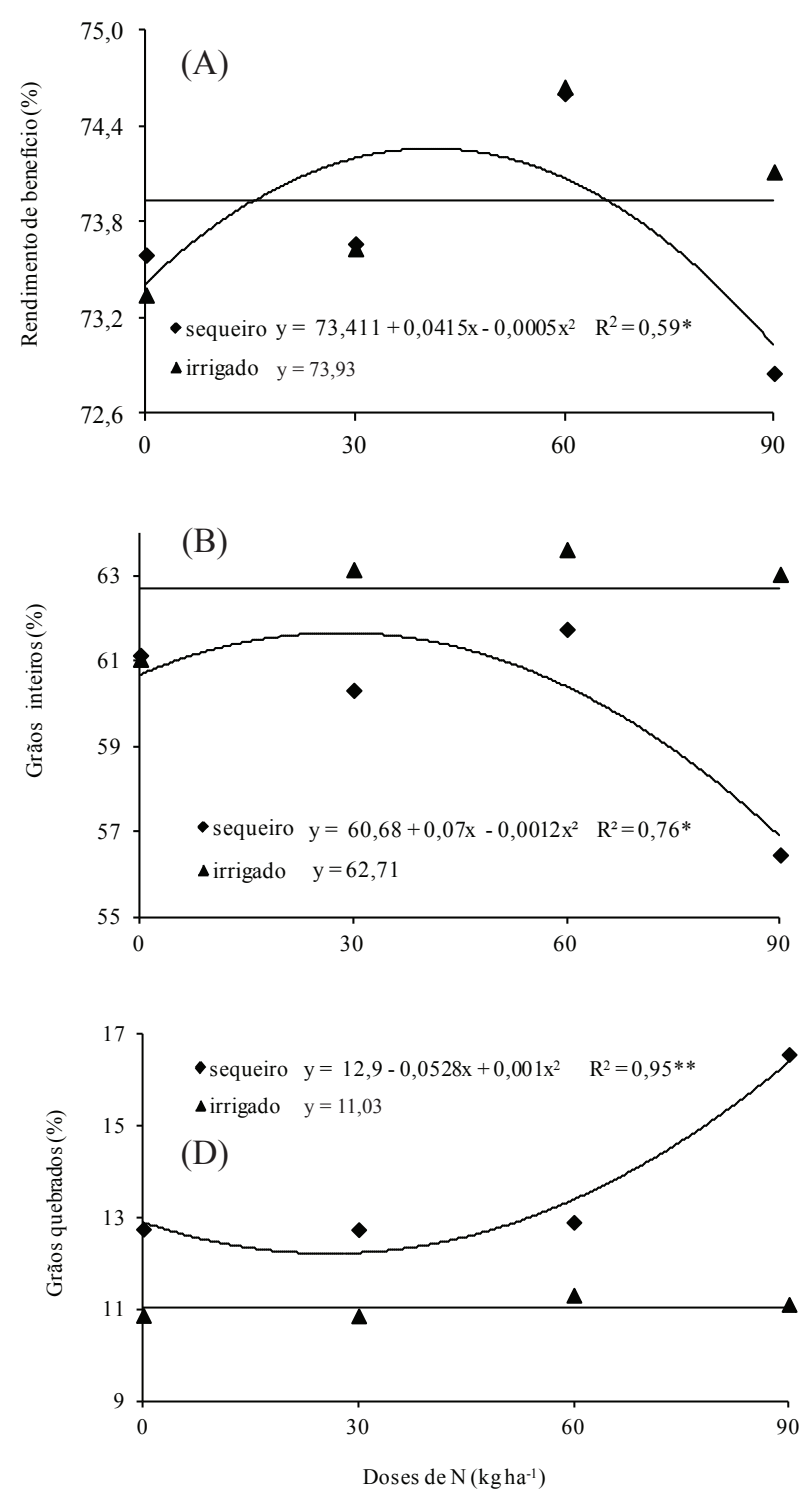

que a aplicação de silício no sulco de semeadura não interferiu no rendimento industrial das cultivares IAC 201 e IAC 202, em cultivo irrigado. Entretanto, esta variável foi influenciada pela interação entre sistemas de cultivo e doses de N (Figura 3A), onde os valores de rendimento, em condições de sequeiro, foram ajustados à equação quadrática, com ponto de máxima eficiência estimado em $41,5 \mathrm{~kg} \mathrm{ha}^{-1}$ de $\mathrm{N}$. Em condições irrigadas, não houve efeito das doses de $\mathrm{N}$ sobre o rendimento de benefício.

Para o rendimento de grãos inteiros, houve interação entre sistemas de cultivo e doses de $\mathrm{N}$ (Figura 3B) e entre silício e doses de N (Figura 3C). Em condições de sequeiro, constatou-se aumento no rendimento de grãos inteiros até o ponto de máxima de $29 \mathrm{~kg} \mathrm{ha}^{-1}$ de N. Não houve efeito das doses de nitrogênio, quando a cultura foi irrigada (Tabela 1). No entanto, os valores encontrados neste sistema de cultivo foram superiores aos obtidos no sistema de sequeiro (Figura 3B).

Esses resultados evidenciam a importância do suprimento adequado de água para a formação e melhoria da qualidade dos grãos (Guimarães et al. 2011). A disponibilidade adequada de água proporciona a
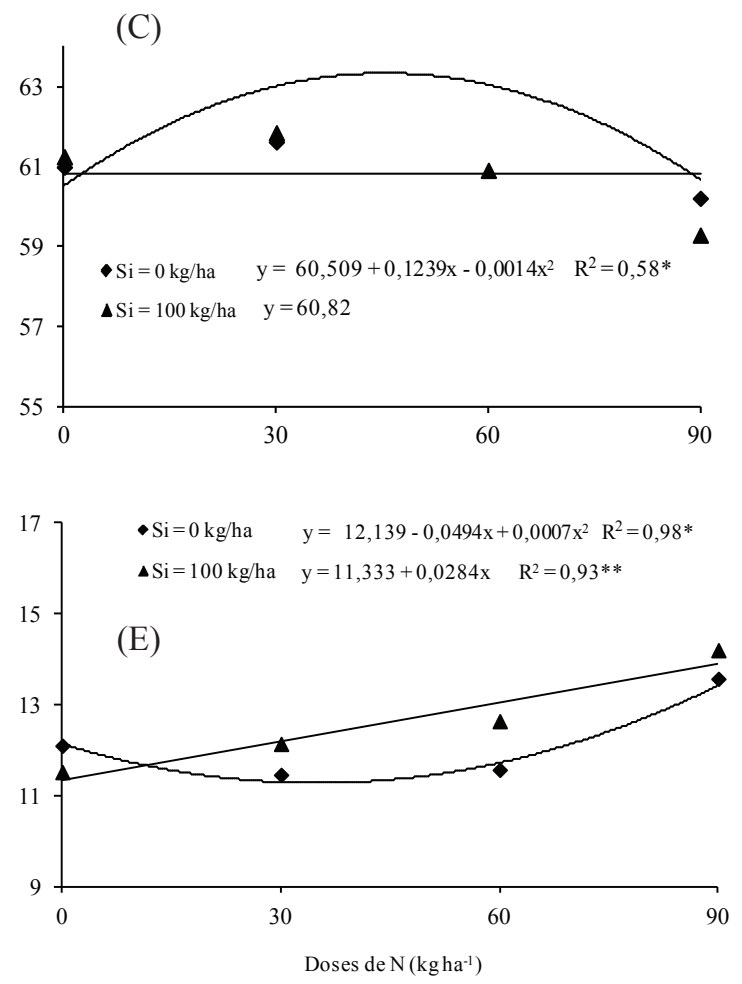

Figura 3. Rendimento de benefício (A) e de grãos inteiros (B e C) e quebrados (D e E) de arroz de terras altas, em função de sistemas de cultivo (sequeiro e irrigado) e adubação (nitrogenada e silicatada) (Selvíria, MS, safra 2006/2007). 
translocação de carboidratos para os grãos, que, bem formados, possuem maior resistência a choques e vibrações proporcionadas pela colheita e pelo beneficiamento, obtendo-se, assim, maior rendimento de grãos inteiros (Arf et al. 2002, Crusciol et al. 2006). O rendimento de grãos inteiros aumentou até a dose de $44 \mathrm{~kg} \mathrm{ha}^{-1}$ de $\mathrm{N}$, quando não houve aplicação de Si (Figura 3E). Não houve efeito significativo da adubação nitrogenada para o rendimento de grãos inteiros, quando aplicados $100 \mathrm{~kg} \mathrm{ha}^{-1} \mathrm{de} \mathrm{Si}$.

Com relação aos grãos quebrados, houve efeito das interações entre sistemas de cultivo e doses de $\mathrm{N}$ (Figura 3D) e entre silício e doses de N (Figura 3E). A percentagem de grãos quebrados foi maior em condições de sequeiro, com o aumento das doses de $\mathrm{N}$ atingindo $16,4 \%$, na dose de $90 \mathrm{~kg} \mathrm{ha}^{-1}$ de $\mathrm{N}$ (Figura 3D). Houve aumento linear na percentagem de grãos quebrados, com o aumento das doses de $\mathrm{N}$, quando aplicados $100 \mathrm{~kg} \mathrm{ha}^{-1}$ de Si (Figura 3E).

A presença de grãos quebrados em lotes de arroz é uma característica indesejável, pois diminui a qualidade e o valor comercial do produto (Arf et al. 2002, Santos et al. 2006). Além disto, pode ocorrer, também, a diminuição da quantidade total de grãos descascados, ou seja, o rendimento de benefício, pois a fração de grãos pode ser eliminada com as cascas (Crusciol et al. 1999).

Com base nos resultados obtidos, foi possível inferir que a utilização de irrigação por aspersão, em conjunto com o aumento das doses de nitrogênio, proporcionou incrementos na maioria dos componentes de produção e, consequentemente, na produtividade, com resposta até a dose de $90 \mathrm{~kg} \mathrm{ha}^{-1}$, além de melhoria na qualidade dos grãos. Por outro lado, no sistema de sequeiro, deve-se dedicar especial atenção à aplicação de maiores doses de nitrogênio, pois esta prática, além de aumentar o custo de produção, pode não se traduzir em aumento da produtividade e nem na melhoria da qualidade de grãos, principalmente se ocorrerem veranicos durante a condução da cultura.

O uso de adubação silicatada não proporcionou incrementos na produtividade e na qualidade de grãos. Assim, apesar de o arroz absorver grande quantidade deste nutriente, provavelmente, a quantidade disponível no solo tenha sido suficiente para suprir as necessidades da planta.

Nesse sentido, outros autores também reportaram ausência de resposta à aplicação de silício, mesmo com doses bem superiores à utilizada no presente trabalho, como relatado por Mauad et al.
(2003), para a cultivar IAC 202, utilizando-se as doses de 0-560 $\mathrm{kg} \mathrm{ha}^{-1}$ de Si, ou Ávila et al. (2010), com a cultivar BRSMG Conai, cultivada em solução nutritiva, nas doses de $0 \mathrm{mg} \mathrm{L}^{-1}$ e $50 \mathrm{mg} \mathrm{L}^{-1}$ de silício, e Mauad et al. (2011), nas doses de $0 \mathrm{~kg} \mathrm{ha}^{-1} \mathrm{e}$ $350 \mathrm{~kg} \mathrm{ha}^{-1}$ de silício, que, também, não obtiveram respostas à aplicação deste nutriente. Desta forma, pôde-se inferir que outros estudos são necessários, para definir em que condições ou níveis de silício no solo se obtém respostas à aplicação deste elemento.

\section{CONCLUSÕES}

1. A irrigação por aspersão aumentou a altura da planta e a produtividade de grãos de arroz.

2. A aplicação de silício no sulco de semeadura não alterou os componentes de produção e a produtividade dos grãos de arroz.

3. A aplicação de doses de silício no sulco de semeadura não interferiu no rendimento industrial da cultivar BRS Primavera, em cultivo irrigado.

4. O aumento das doses de N, no sistema irrigado por aspersão, incrementou a altura, número de colmos e de panículas $\mathrm{m}^{-2}$, número total de espiguetas e a produtividade de grãos, no entanto, no sistema de sequeiro, a produtividade de grãos foi reduzida.

\section{AGRADECIMENTOS}

À Fundação de Amparo à Pesquisa do Estado de São Paulo (FAPESP), pelo financiamento da pesquisa, e ao Conselho Nacional de Desenvolvimento Científico

e Tecnológico (CNPq), pela concessão de bolsa de produtividade em pesquisa ao segundo e terceiro autores

\section{REFERÊNCIAS}

ARF, O. et al. Preparo do solo, irrigação por aspersão e rendimento de engenho do arroz de terras altas. Scientia Agricola, Piracicaba, v. 59, n. 2, p. 321-326, 2002.

ÁVILA, F. W. et al. Interação entre silício e nitrogênio em arroz cultivado sob solução nutritiva. Revista Ciência Agronômica, Fortaleza, v. 41, n. 2, p. 184-190, 2010.

BALASTA, M. L. F. et al. Effects of silica level on some properties of Oryza sativa straw and hull. Canadian Journal of Botany, Guelph, v. 67, n. 8, p. 2356-2363, 1989.

BARBOSA FILHO, M. P.; FONSECA, J. R. Importância da adubação na qualidade do arroz. In: SÁ, M. E.; BUZETTI, S. Importância da adubação na qualidade dos produtos agrícolas. São Paulo: Ícone, 1994. p. 217-231. 
COMPANHIA NACIONAL DE ABASTECIMENTO (Conab). Produção de grãos: safra 2010/11: $4^{\circ}$ levantamento. Disponível em: <www.conab.gov.br>. Acesso em: 05 dez. 2011.

CRUSCIOL, C. A. C. et al. Rendimento de benefício e de grãos inteiros em função do espaçamento e da densidade de semeadura do arroz de sequeiro. Scientia Agricola, Piracicaba, v. 56, n. 1, p. 47-52, 1999.

CRUSCIOL, C. A. C. et al. Yield of upland rice cultivars in rainfed and sprinkler-irrigated systems in the Cerrado region of Brazil. Australian Journal of Experimental Agriculture, Collingwood, v. 46, n. 11, p. 1515-1520, 2006.

CRUSCIOL, C. A. C. et al. Water supplied by sprinkler irrigation system for upland rice seed production. Bioscience Journal, Uberlândia, v. 28, n. 1, p. 34-42, 2012.

DOORENBOS, J.; PRUITT, W. O. Las necesidades de agua de los cultivos. Roma: FAO, 1976. (Riego y drenaje, 24).

EMPRESA BRASILEIRA DE PESQUISA AGROPECUÁRIA (Embrapa). Sistema brasileiro de classificação de solos. Rio de Janeiro: Embrapa/CNPSo, 1999.

FAGERIA, N. K. et al. Yield and yield components of upland rice as influenced by nitrogen sources. Journal of Plant Nutrition, Philadelphia, v. 34, n. 3, p. 361-370, 2011.

GOMES, C. F. et al. Disponibilidade de silício para a cultura do arroz, em função de fontes, tempo de incubação e classes de solo. Pesquisa Agropecuária Tropical, Goiânia, v. 41, n. 4, p. 531-538, 2011.

GUIMARÃES, C. M. et al. Sistema radicular do arroz de terras altas sob deficiência hídrica. Pesquisa Agropecuária Tropical, Goiânia, v. 41, n. 1, p. 126-134, 2011.

GUTIERREZ, R. S. et al. Extração de silício em solos fertilizados com fosfato e silicato. Pesquisa Agropecuária Tropical, Goiânia, v. 41, n. 1, p. 1-7, 2011.

HEINEMANN, A. B.; STONE, L. F. Efeito da deficiência hídrica no desenvolvimento e rendimento de quatro cultivares de arroz de terras altas. Pesquisa Agropecuária Tropical, Goiânia, v. 39, n. 2, p. 134-139, 2009.
MA, J. F. et al. A silicon transporter in rice. Nature, New York, n. 440, p. 688-691, 2006.

MAUAD, M. et al. Teores de silício no solo e na planta de arroz de terras altas com diferentes doses de adubação silicatada e nitrogenada. Revista Brasileira de Ciência do Solo, Viçosa, v. 27, n. 5, p. 867-873, 2003.

MAUAD, M. et al. Produção de massa seca e nutrição de cultivares de arroz de terras altas sob condição de déficit hídrico e adubação silicatada. Semina Ciências Agrárias, Londrina, v. 32, n. 3, p. 939-948, 2011.

MENEZES, B. R. S. et al. Caracterização morfoagronômica em arroz vermelho e arroz de sequeiro. Pesquisa Agropecuária Tropical, Goiânia, v. 41, n. 4, p. 490-499, 2011.

NASCENTE, A. S. et al. Produtividade do arroz de terras altas em função do manejo do solo e da época de aplicação de nitrogênio. Pesquisa Agropecuária Tropical, Goiânia, v. 41, n. 1, p. 60-65, 2011.

PINHEIRO, B. S. et al. Tipo de planta, regime hídrico e produtividade do arroz de sequeiro. Pesquisa Agropecuária Brasileira, Brasília, DF, v. 20, n. 1, p. 85-87, 1985.

PRABHU, A. S. et al. Soluble tissue sugar content and leaf blast severity in response to the application of calcinated serpentinite as a silicon source in irrigated rice. Summa Phytopathologica, Botucatu, v. 33, n. 4, p. 402-404, 2007.

RAIJ, B.V. et al. Análise química para avaliação da fertilidade de solos tropicais. Campinas: Instituto Agronômico, 2001.

REIS, M. A. et al. Aplicação de silício em arroz de terras altas irrigado por aspersão. Acta Scientiarum Agronomy, Maringá, v. 30, n. 1, p. 37-43, 2008.

RODRIGUES, R. A. F. et al. Manejo de água em arroz de terras altas no sistema de plantio direto, usando o tanque Classe A. Engenharia Agrícola, Jaboticabal, v. 24, n. 3, p. 546-556, 2004.

SANTOS, A. B. et al. A cultura do arroz no Brasil. 2. ed. Santo Antônio de Goiás: Embrapa Arroz e Feijão, 2006. 